Abstract ID: 18

\title{
Association of academic stress \& performance in continuous assessment among pharmacy students in body system course
}

May Khin Soe | Mohamad Sharul Fahmi Baharudin

Kulliyyah of Pharmacy, International Islamic University Malaysia

Introduction: Undergraduate Pharmacy students find the program is stressful. This study compares the perceived stress score (PSS) of third year Pharmacy students and their performance via continuous assessment (CAM) in a body system course. Methods: The relationship between the PSS and their academic performance, though out the semester were explored for 114 students including 25 male and 85 female. In this cross-sectional study, questionnaires were distributed to assess their PSS, other relevant questions and the result in four quizzes on the course were recorded periodically and analyzed descriptively. Results: The mean value of the whole class PSS score was found $(38.66 \pm$ 6.46). Females' PSS in 1 st quiz was $38.76 \pm 5.56$ and male's was $39.21 \pm 5.48$ and quiz 2 for female was $38.61 \pm 6.27$ whereas $40.1 \pm 7.48$ in male. That value in quiz 3 and 4 for female was $38.10 \pm 7.18$ and male was $39.69 \pm 8.68$. However, there is no significant difference in gender. The PSS score for all participants was found highest in the second quiz $(38.99 \pm 6.60)$ whereas the mean marks they obtained were lowest $(4.97 \pm 1.36)$ compared to other quizzes but their relation is weakly significant. Total scoring of the CAM for the whole class was found even lower compared to previous batches, $23.83 \pm$ 3.88. They were engaged with various co-curriculum activities and complained of not having enough time to study and revise. The unsatisfactory performance might be due to heavy topics and time constraint. Conclusions: Stress and time management are critical elements for undergraduate students to perform well academically regardless of their stress level.

KEYWORDS: perceived stress score, continuous assessment, academic performance, body system, undergraduate pharmacy student 